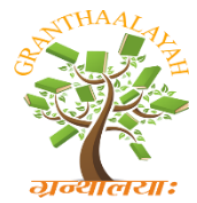

\author{
INTERNATIONAL JOURNAL OF RESEARCH - \\ GRANTHAALAYAH \\ A knowledge Repository
}

Science

\title{
OPERATIONAL STATUS OF MANAGEMENT INFORMATION SYSTEMS OF STATE UNIVERSITIES AND COLLEGES IN SAMAR- LEYTE ISLANDS
}

\author{
Jose P. Ching, Jr., DM ${ }^{* 1}$ \\ ${ }^{* 1}$ Information Technology Department, College of Science, Philippines
}

\begin{abstract}
This paper aims to determine the MIS unit's operational status and the performance level of information systems of the state universities and colleges in the Samar-Leyte Islands. In order to determine and appreciate the value and importance of MIS unit's services, the unit requires a review of its profile and ICT resources. The theory of Information System success model of DeLone and McLean was then used for evaluation to measure the performance and effectiveness of IS in terms of system, information, service quality, use (intention to), user satisfaction and net benefits. The profile of MIS units identified each its capacity and characterized the performance and quality of IS.
\end{abstract}

Keywords: Management Information System; Information System; Information Communication Technology; DeLone and McLean IS success model; Operational.

Cite This Article: Jose P. Ching, Jr.. (2019). “OPERATIONAL STATUS OF MANAGEMENT INFORMATION SYSTEMS OF STATE UNIVERSITIES AND COLLEGES IN SAMARLEYTE ISLANDS." International Journal of Research - Granthaalayah, 7(3), 148-157. https://doi.org/10.29121/granthaalayah.v7.i3.2019.955.

\section{Introduction}

The Management Information System (MIS) describes the significant aspect which involves organizing, management and development of information system to support organizational activities and its future plans to improve administrative functions, decision-making, and functions in delivering Information Communication Technology (ICT) services. MIS provides several benefits to the business organization and educational institution and also provides a valuable timesaving benefit to the workforce. With faster access to needed information (Reddy, et. al., 2009). Information systems classifies transaction processing system that captures and processes data about business transactions and information systems for MIS that provides for managementoriented reporting based on transaction processing and operations of the organizations (Whitten, et al., 2004). Most organization especially educational institutions, information systems (IS) tend to manage data, provide useful information, and deliver specific functions that supports the organization and to valued stakeholders. In this definition, information systems are typically 
application programs or computer systems that serves to a specific function and present accurate and up-to-date information. Computer-based information system greatly enhances the success of an organization. In terms of organizational efficiency, information systems minimize the cost, time, and processing of information resources. Likewise, they effectively support the organization's structure and culture, and increase the business value of the enterprise in the highly competitive global economy (Canizares, 2005). On the other hand, ICT resources and services may take place to an approach for the IT solutions to the organizations that needs supports in developments and expansion of information system and technology.

\subsection{ICT Resources and Services}

ICT resources may consist of several components: computer equipment, application programs, system software, IT experts' personnel and services. In this study, the initiative of MIS units is to offer ICT services and resources to facilitate the operational condition and situation of an organization. The issue had conceptually observed in ICT resources as a primary concern among the institutions and organizations which affects the operation and services of the unit. This concern needs to work for hardware improvements, update in software, enhance skills of the personnel and better services. These are the basis to describe enhancements of the office operation in terms of the IT facilities and technology acquisition. On the other hand, ICT services may take place to an approach for the IT solutions to the organizations that needs supports in developments and expansion of information system and technology.

In order for the organization to come up with an effective information system and MIS unit, there should be a concrete policy that binds other departments to work together. To implement the organizations', work plan, organized set of activities, established appropriate project assignment, trained personnel and designated right positions to qualified individuals that can initially handle and manage situations. This could be a good strategy in providing a better performance and achieving organizational goals. An effective and efficient system of management in information technology in the different SUCs, needs a periodic consultation with prospective IT personnel, monitoring of supplies and continuous updating of IT policies and regulations in the institutions. There should be a continuous, comprehensive, and realistic evaluation of the IT unit in order to find out the viability and suitability of its programs to the present needs of the community and service areas. Somoray (2009), a continuous monitoring and evaluation is needed because of the fast growing IT development. The existence of the MIS units is identified among the SUCs in Samar-Leyte Islands which describes the number of years they have been given services and delivery of ICT operations to its stakeholders and to the institution/organization.

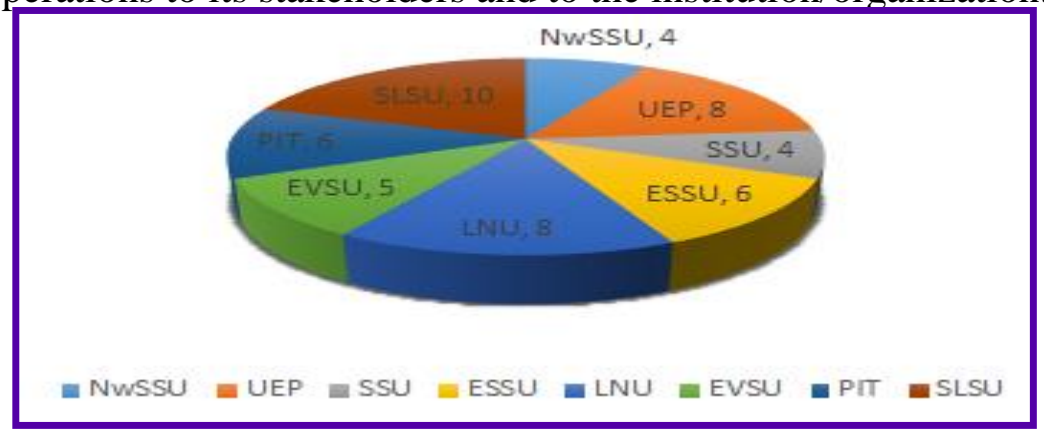

Figure 1: Number of Years of Existence of the MIS Units in the Samar-Leyte SUCs 
As to the number of years of existence of the MIS unit in the eight state universities in the SamarLeyte Islands, Figure 1 shows that the SLSU was the oldest, with 10 years of operation. The NwSSU and the SSU had the least number of years of MIS operation. That the existence of the MIS units in the SUCs in the Samar-Leyte Islands varies in number of years is an indication of the continuous development of the information systems and their operations.

This paper aims to determine the profile and operational status of the MIS unit of SUCs in SamarLeyte Islands and measures the stability, effectivity, user satisfaction, quality of operation, and impact of information systems management and services.

\subsection{DeLone \& McLean IS Success Model}

The D\&M model has also been found to be a useful framework for organizing IS success measurements. The model has been widely used by IS researchers for understanding and measuring the dimensions of IS success (Peter, Delone, \& McLean, 2008). According to Keen as cited by DeLone and McLean, Keen's view of information systems, the evaluation of the effectiveness or success of information systems is an important aspect of information systems field in both research and practice. However, the manner in which they evaluate the success of an information system has changed over time as the context, purpose, and impact of IT has evolved. It is therefore, essential to understand the foundations and trends in IS success measurement and what they mean for the future (DeLone \& McLean, 2016).

The six dimension of IS success were identified as system quality, information quality, service quality, use (intention to), user satisfaction and net benefits. The IS model has been adapted to manage the information systems and measure the stability and quality of the IT operation. The performance and status of the SUCs MIS unit operation in the Samar-Leyte Islands categorize and describes the classification of the information systems conditions, and measured through the IS success model of DeLone and McLean.

\subsection{System Quality}

The increase of organizational dependence on management information systems drives management attention towards improving systems' quality. As IT quality is a multidimensional measure, it is important to determine what aspects of IT quality are critical to organizations to help Chief Information Officers (CIOs) to devise effective IT quality improvement strategies (Gorla, Somers \& Wong, 2010). Considering the quality of ICT services, the quality of the system effectively operates a productive results and performance.

\subsection{Information Quality}

The empirical findings of Zaied (2012), reached several conclusions. First, the empirical analysis indicated that information quality has a strong significant influence on the IS success. Thus, system designers should make full use of the completeness; understandability; security; availability; and accuracy of information to increase behavioral intention and user satisfaction. Second, system designers should actively seek methods of improving system security; system availability; system compatibility; system privacy; and system maintainability since these 
elements significantly affect the IS success. Third, the improvement of information system through enhancing information quality, perceived usefulness, service quality, and perceived ease of use will foster user involvement, behavioral intention, and user satisfaction. Finally, the proposed model and its elements proved that it can be used as a beneficial tool for decision makers in organizations on evaluating the implementation of information systems.

\subsection{Service Quality}

The success dimension service quality represents the quality of the support that the users receive from the IS department and IT support personnel, such as, for example, training, hotline, or helpdesk (Sharda and VoB, 2012). A field study examined the expectations of users as they related to the quality of service offered by the Information Systems (IS) function within organizations. The users have consistently high expectations both within and across organizations. The SERVQUAL or service quality dimensions, tangibles (physical facilities, equipment \& appearance of personnel), reliability, responsiveness, assurance and empathy as possible causes for this consistency along with ways that management can intervene in order to influence user expectations (Miller, Jones, \& Winick, 2007).

\subsection{Intention to (Use)}

The success dimension (intention to) use represents the degree and manner in which an IS is utilized by its users. Measuring the usage of an IS is a broad concept that can be considered from several perspectives. In case of voluntary use, the actual use of an IS may be an appropriate success measure. Previous studies measured use objectively by capturing the connect time, the functions utilized, or the frequency of use. As the amount of time a system is used is apparently not a sufficient success measure, other studies applied subjective measures by questioning users about their perceived use of a system (DeLone, 1988).

\subsection{User Satisfaction}

One of the dimension to measure the success of an information system is user satisfaction. IS researchers have long measured the success of an IS system by the measurement of user satisfaction (Frejik \& Powell, 2015). The users of information system are literally those who interact with the applications. Users determine the level of satisfaction based on the IS functionality. The user's satisfaction does not imply user's knowledge and literacy in using the computer; rather this indicates the appropriate delivery of the system and responses.

\subsection{Net Benefits}

Benefits management identifies goals and benefits by combining organizational changes and investments in IS/IT, and also by showing the way to achieve them (Gomes, \& Romão, 2013). "To guide the actual realization of benefits, Ward and Daniel (2006) state that organizations should embrace and recognize with benefits management. They define this activity as "the process of organizing and managing such that the potential benefits arising from the use of information systems are actually realized". 


\section{Methodology}

The study, a descriptive-correlational research, involves collecting information through data review, surveys, interviews or observation. Correlational research determines the relationships that exist between two or more variables. Theoretically, any two variables can be correlated (Gan, 2012).

The evaluation of the MIS units of state universities in Samar-Leyte Islands uses a constructive survey questionnaire for obtaining data and information to the study. The sets of questionnaires are constructed to identify the availability of ICT resources and associated with the six dimensions of IS success model to measure the performance MIS operation and IS quality. The methods were justified by the perception of the school administrators, IT personnel, and senior year students.

In 1992, DeLone \& McLean suggested that researchers should "systematically combine individual measures from the IS success categories to create comprehensive measurement instrument". The six dimensions in their model share a dependent relationship as well as temporal and causal relationships. The authors contend that "system quality" and "information quality" singularly and jointly affect both "use" and "user satisfaction". Also both are direct antecedents of "individual impact" which ultimately have some "organizational impact" (DeLone \& McLean, cited by Kandari, 2010).

\subsection{Respondents and Procedure}

Identified as respondents were school administrators, MIS personnel, and the senior students of the eight (8) state universities in the Samar-Leyte Islands. Twenty-five percent of the population was used to determine the sample size for each classification in each state university. The respondents were given questionnaires to elicit the necessary data and information. They are classified as system users who handle and manage the ICT operations and performs day-to-day interactions with the information system.

Table 1: Frequency and Percentage Distribution on the Respondents of the Study

\begin{tabular}{|l|l|l|l|l|l|l|l|l|}
\hline State Universities and Colleges & \multicolumn{2}{l}{ Administrators } & \multicolumn{2}{l|}{ IT Staff } & \multicolumn{3}{l|}{ Senior Students } & \multicolumn{2}{l|}{ Total } \\
\cline { 2 - 10 } & $\mathbf{f}$ & $\mathbf{\%}$ & $\mathbf{f}$ & $\mathbf{\%}$ & $\mathbf{F}$ & $\mathbf{\%}$ & $\mathbf{f}$ & $\mathbf{\%}$ \\
\hline 1. Leyte Normal University & 10 & 10.20 & 6 & 14.63 & 164 & 11.63 & 180 & 11.62 \\
\hline 2. Northwest Samar State University & 14 & 14.29 & 5 & 12.20 & 182 & 12.91 & 201 & 12.98 \\
\hline 3. University of Eastern Philippines & 15 & 15.31 & 8 & 19.51 & 290 & 20.57 & 313 & 20.21 \\
\hline 4. Palompon Institute of Technology & 14 & 14.29 & 4 & 9.76 & 92 & 6.52 & 110 & 7.10 \\
\hline 5. Eastern Visayas State University & 16 & 16.33 & 4 & 9.76 & 201 & 14.26 & 221 & 14.27 \\
\hline 6. Samar State University & 9 & 9.18 & 2 & 4.88 & 107 & 7.59 & 118 & 7.62 \\
\hline 7. Eastern Samar State University & 12 & 12.24 & 7 & 17.07 & 241 & 17.09 & 260 & 16.79 \\
\hline 8. Southern Leyte State University & 8 & 8.16 & 5 & 12.20 & 133 & 9.43 & 146 & 9.43 \\
\hline TOTAL & 98 & 100.00 & 41 & 100.00 & 1410 & 100.00 & 1549 & 100.00 \\
\hline
\end{tabular}

System users' satisfaction is often used for the assessment of information system functionality performance. The relation between the Information System user and Information System functionality is very complex, since the Information System user's satisfaction depends on the 
interaction between a user and the Information System, which determines the user's subjective rating on increased quality of his/her work. Nowadays, experts use a number of different instruments for measuring user's satisfaction with the Information System, among which several are particularly emphasized: (a) the relation between user and Information, Technology professionals, (b) definition of demands for change in Information System, (c) current and prompt information, (d) user's level of training for work with Information System, (e) quality of output information, (f) quality of available documentation and (g) user's level of dependence on the Information System, (Platiša \& Balaban 2009).

\subsection{Instrumentation and Validation}

The research questionnaire was prepared to measure different conceptual and technical issues in information technology. A set of questions was also formulated to identify and describe the MIS unit profile, the ICT budget, the ICT resources in operation, and the six dimensions for IS success model.

MIS profile. This described the management information system department's profile into three: years of existence as MIS department, the number of MIS personnel/employee, and the ICT Budget.

ICT Resources (MIS Operation). This contains the ICT resources for operations namely: hardware (the equipment, networking and other components), software (application programs and system software) and peopleware (identified through the IT personnel skills and system/application users).

The six major dimensions of D\&M IS Success model namely system quality, information quality, service quality, intention to use, user satisfaction, and net benefits were used in the survey with five numerical options to determine the rating for each answered items. This part of the questionnaire utilized a rating scale of 1 to 5 where 5 means "Excellent"; 4, "Very Satisfactory"; 3, "Satisfactory"; 2, "Unsatisfactory" and 1 "Poor".

The validation of the instrument was conducted in the Naval State University a state university in Biliran Island. The MIS unit in Naval State University operationally has quality and good performance in providing ICT services in the institution. The instrument was presented and discussed to the identified respondents. The dry run was done to test the reliability of the instruments for the profile and MIS operation of management information systems in SUCs. The data gathered during the dry run was analyzed by a statistician to determine the instrument's reliability.

The guidelines and procedure in administering the questionnaire for the data collection was also prepared and followed to sustain the validity of the instrument. Table 2 shows the result of the reliability test for the status of the MIS operation in the Samar-Leyte SUCs during the dry run. The table shows the number of items of the category and the results of the reliability coefficient. The interpretation showed excellent results for the six categories or dimensions of the IS success model. 
Table 2: Status of the Management Information System Operations in the Samar-Leyte SUCs

\begin{tabular}{|l|l|l|l|}
\hline Category & Number of Items & Reliability Coefficient & Interpretation \\
\hline System Quality & 8 & 0.93 & Excellent \\
\hline Information Quality & 8 & 0.94 & Excellent \\
\hline Service Quality & 8 & 0.96 & Excellent \\
\hline Intention to Use & 8 & 0.92 & Excellent \\
\hline User Satisfaction & 8 & 0.96 & Excellent \\
\hline Net Benefits & 8 & 0,96 & Excellent \\
\hline Overall Result & 48 & 0.99 & Excellent \\
\hline \multicolumn{2}{|l|}{ Legend: (De Guzman-Santos, 2007) } & 0.90 and above $\quad$ - Excellent Reliability \\
\multicolumn{2}{|l}{$0.80-0.89$} & - Very Good Reliability \\
& $0.70-0.79$ & - Good Reliability \\
& $0.60-0.69$ & - Somewhat Low Reliability \\
& $0.50-0.59$ & - Needs Revision
\end{tabular}

The six categories of the D\&M IS success model tested were found to be excellent; therefore, the data gathering instrument was found reliable.

\section{Results and Discussion}

In this research, the MIS unit's operations were placed to determine the availability of its ICT resources and quality of services as well as the six dimension of information system success model which evaluates the performance and quality of information systems.

Among the eight SUCs studied, the MIS unit exists and operationally serve the school in several years from its implementation to present and provide the IT services. The ICT resources describe common and advance component of hardware equipment, software applications, and program, personnel involved in IT, and the services. The ICT resources of each SUCs have distinct positions in utilizing technology, the availability of its components and the method how they serve full responsibilities to the operation. The initiative of the administrator is a factor that sustains the needs of the unit in terms of ICT infrastructure. The adequacy of financial support for ICT has equipped the unit/organization to improve the ICT facilities and equipment. This variation is an indication that shows enhancement and continuous development of information systems and improvement of the information system's quality of service and operations. Moreover, the aide of IT personnel has provided the factor to overcome situations and technical problems in terms of computer facilities, networking, internet access, programs and software issues. However, the identified applications and information systems used were cashiering, enrolment, grades inquiry and payroll system which have also acquired by the SUCs through an outsourcing initiative and in-house development.

The performance level of the operational status of the MIS unit proved its effectiveness. The respondents identified the characteristics of information systems and understood the information systems dimensions in the evaluation of the operations of the MIS unit. The results justify the importance and value of the six IS dimensions, especially when dealing with the information systems' functions and processes. 
Table 3: Respondents' Perceptions of the Status of MIS Operations in the Samar-Leyte SUCs

\begin{tabular}{|c|c|c|c|c|c|c|c|c|c|c|c|c|}
\hline \multirow[b]{3}{*}{ MIS Operations } & \multicolumn{12}{|c|}{ Perceptions of the Respondents } \\
\hline & \multicolumn{3}{|c|}{ Administrators } & \multicolumn{3}{|c|}{ IT Staff } & \multicolumn{3}{|c|}{\begin{tabular}{|l|} 
Students \\
\end{tabular}} & \multicolumn{3}{|c|}{ Overall Mean } \\
\hline & $\bar{x}$ & Int. & SD & $\bar{x}$ & Int. & SD & $\bar{x}$ & Int. & SD & $\bar{x}$ & Int. & SD \\
\hline 1. System Quality & 3.83 & VS & 0.59 & 4.33 & VS & 0.52 & 3.76 & VS & 0.63 & 3.97 & VS & 0.58 \\
\hline 2. Information Quality & 3.65 & VS & 0.69 & 4.41 & VS & 0.55 & 3.78 & VS & 0.69 & 3.95 & VS & 0.64 \\
\hline 3. Service Quality & 3.66 & VS & 0.74 & 4.32 & VS & 0.65 & 3.66 & VS & 0.71 & 3.88 & VS & 0.70 \\
\hline 4. Intention to Use & 3.69 & VS & 0.71 & 4.35 & VS & 0.65 & 3.77 & VS & 0.69 & 3.94 & VS & 0.68 \\
\hline 5. User Satisfaction & 3.58 & VS & 0.68 & 4.23 & VS & 0.69 & 3.73 & VS & 0.70 & 3.85 & VS & 0.69 \\
\hline 6. Net Benefits & 3.76 & VS & 0.65 & 4.38 & VS & 0.65 & 3.85 & VS & 0.71 & 4.00 & VS & 0.67 \\
\hline Overall Mean & 3.70 & VS & 0.68 & 4.34 & VS & 0.62 & 3.76 & VS & 0.69 & 3.93 & VS & 0.66 \\
\hline
\end{tabular}

The result shows that the administrators, IT staff, and students are very satisfied with the MIS operations in terms of system quality, information quality, service quality, intention to use, user satisfaction and net benefits. This means also that the respondents understood procedure and gained knowledge of the processes involved in the operation of the MIS unit. Thus, improvements and development must be advised, since the ICT needs always to be up-to-date and assessed.

\section{Conclusions and Recommendations}

The ICT resources and information systems six dimensions of DeLone and McLean IS success model were effective, appropriate, useful and easy to understand. The results and analysis of the study show that the IS success model can measure the performance of MIS units, as well as the operation which supports the services provided by the MIS units.

The existence of the MIS unit had leveled-up and upgraded their ICT facilities and equipment. Furthermore, the number of years that the MIS units existed had also improved the quality of services to their clients and strengthen the ICT performance. The experts' IT personnel had justified their performance to their tasks. This is a manifestation that the MIS employees, whether regular or on job order can do the duties and take on responsibilities to prepare, manage, and serve the SUCs.

On the financial side, the ICT budget allocation is adequate for the ICT infrastructure particularly in preparing for the facilities needed for the MIS operations. The ICT budget provides for improvements and enhancement of the information technology, whatever approach for the development of IS (in-house or outsourced) wherein the support to the operations and other technical issues could bring a solution to the SUC MIS unit performance and services.

The association of the six dimensions of the information systems model proved that the importance of the information system process made the MIS units' operation effective. The approach was initially the factor to determine the reliability, accuracy, convenient, efficient, flexible and the functionality of the IS which the consolidation of the operation is effective.

The operational status of the MIS units' system quality, information quality, service quality, intention to use, user satisfaction, and net benefits, were perceived by the administrators, IT staff, and students as very satisfactory, which implied that evaluation is a primary concern to sustain the MIS efficiency of operation. 
The state universities should consider the program plan for the process of recognizing some issues particularly in information technology. An assessment and continuous monitoring of the MIS units to seek updates and providing visibility to the components of ICT. School administrators should also consider allocation of ICT budget especially on hardware components, facilities, equipment and software to increase performance of the operation.

There should also be a thorough assessment from the users through the information systems; system quality, information quality, service quality, intention to use, user satisfaction and the net benefits to check the stability of the operation. The MIS unit should recommend to the administration to simplify and clarify policies and procedures which could help concerned officials perform their functions effectively and come up with rational decisions. This strategy will justify administrative functions that determine the quality assurance of the unit and improve adequacy of information, services of management and other areas that need attention and improvement for the operation of the MIS unit, users, and the organization.

\section{Acknowledgements}

I would like to extend my heartfelt thanks to the persons who encouraged and assisted me in the preparation for the successful accomplishment of this research study.

First, to GOD ALMIGHTY, for the strength, hope and guidance to finish and complete this research.

Dr. Lydia E. Dela Rosa, for her motherly concern and patiently taking time to edit my manuscript in order to make this as best as possible.

Dr. Karina Milagros C. Lim, batch, dean of the College of Science, UEP, for her motivation and encouragement to finish my research study.

To Chinchin, for her valuable time, motivation, and encouragement especially in providing research references, pointers and research notes, which lead me to start writing this research study.

To Celeste Chan, for her assistance and valuable time she spend in accompanying me during my library visit in other schools.

My family Josette and my daughters Trisha Ferbry and Samantha Lian who serve as joy and inspiration to complete this research.

Thank you!

jojo

\section{References}

[1] Canizares, Raymundo, 2005, Information System of TTMIST Basis for a Five-Year Information System Strategic Plan, Master in Public Management, Thesis Published 2005.

[2] DeLone, W. H. and McLean, E.R., Information Systems Success Measurement, "Foundations and Trends in Information Systems", Vol. 2, No. 1, p 10. 
[3] DeLone, W. H. (1988). Determinants of success for computer usage in small business. MIS Quarterly, 12(1), 50-61.

[4] Frejik, Michael D. and Powell, Anne, "User Satisfaction with ERP Implementations: A Literature Review" (2015). MWAIS 2015 Proceedings. Paper 25. http://aisel.aisnet.org/mwais2015/25

[5] Gan, Maiden G.A., 2012. Conflict Management Styles and Personality Types of School Administrators of State Universities in Samar Island, Dissertation Doctor of Management, Northwest Samar State University.

[6] Gomes, J., \& Romão, M., (2013). Information Systems and Technology Projects in Healthcare Organisations. ResearchGate International Publication, url:

https://www.researchgate.net/publication/280064220_Information_Systems_and_Technology_Pr ojects_in_Healthcare_Organisations.

[7] Kandari, Jaikrit Singh, "Information Quality on the World Wide Web: A User Perspective" (2010), Industrial and Management Systems Engineering -- Dissertations and Student Research.

[8] Marcial, Dave E., Information Technology Resources in the Higher Education Institution in the

[9] Philippines, College of Computer Studies, Silliman University, Philippine IT Journal. 2012

[10] Miller, Robert; Jones, Thomas; and Winick, Lee, "INFORMATION SYSTEMS SERVICE QUALITY: AN EXAMINATION OF USER EXPECTATIONS" (2007). MWAIS 2007 Proceedings. Paper 36. http://aisel.aisnet.org/ mwais2007/36

[11] Palmius, J., "Criteria for Measuring and Comparing Information Systems", Proceedings of the 3oth Information Systems Research Seminar in Scandinavia IRIS 2007

[12] Petter, S., DeLone, W. \& McLean, E., "Measuring information systems success: models, dimensions, measures, and interrelationships", European Journal of Information Systems (2008) 17: 236. https://doi.org/10.1057/ejis.2008.15

[13] Platiša, Gordana, Balaban, Neđo, Methodological Approaches to Evaluation of Information System Functionality Performances and Importance of Successfulness Factors Analysis, Accepted 24 April 2009, Vol. 4 (2009), No. 2, pp. 011-017.

[14] Ramesh Sharda, and Stefan Voß, (2012), Information Systems Theory, Explaining and Predicting Our Digital Society, Vol. 1

[15] Reddy, G.S., Srinivasu, S.R., Rikkula, S.R. \& Rao, V.S., 2009. Management Information System to Help Managers for Providing Decision Making in an Organization. International Journal of Review in Computing. p 1.

[16] Somoray, Ma. Judy M., 2009, Implementation of Management Information System in State Universities and Colleges, Region VIII, Philippines, Dissertation, NwSSU 2009.

[17] Ward, J., and Daniel, E., (2006), Benefits management: Delivering value from IS \& IT investments, John Wiley \& Sons Ltd., Chichester, ISBN: 978-0-470-09463-1

[18] Whitten, Jeffrey L., Bentley, Lonnie D., \& Dittman, Kevin C., (2004), System Analysis and Design Methods, 6th Edition, Purdue University, West Lafayette, IN, McGraw-Hill Co., p6.

[19] Zaied, Abdel Nasser H., An Integrated Success Model for Evaluating Information System in Public Sectors, Journal of Emerging Trends in Computing and Information Sciences (C2009-2012 CIS Journal. All rights reserved. College of Computers and Informatics, Zagazig University, Egypt, VOL. 3, NO. 6, July 2012 ISSN 2079-8407, url: http://www.cisjournal.org

\footnotetext{
*Corresponding author.

E-mail address: josepchingjr@ gmail.com
} 